\title{
Interlocking Block Masonry (ISSB) for Sustainable Housing Purposes in Thailand, With Additional Examples From Cambodia and Nepal
}

\author{
Jan Bredenoord ${ }^{1}$, Wutinai Kokkamhaeng ${ }^{2}$, Pichit Janbunjong ${ }^{2}$, Ongarj Nualplod ${ }^{2}$, Suwatchai Thongnoy ${ }^{2}$, \\ Wasana Khongwong ${ }^{2}$, Piyalak Ngernchuklin ${ }^{2} \&$ Aparat Mahakhant ${ }^{2}$ \\ ${ }^{1}$ Independent urban planner and housing researcher, former research fellow Utrecht University. \\ ${ }^{2}$ Researchers and officials of Thailand Institute of Scientific and Technological Research (TISTR) \\ Correspondence: Jan Bredenoord, Housing Research, Amerikaring 26, 3823 TH Amersfoort, The Netherlands.
}

Received: August 8, 2019

doi:10.5539/emr.v8n2p42
Accepted: September 18, 2019 Online Published: September 20, 2019

URL: https://doi.org/10.5539/emr.v8n2p42

\begin{abstract}
This paper is about Interlocking Stabilized Soil Blocks (ISSB) as developed in Thailand. ISSB are seen as an eco-friendly building material for home building and structures such as water tanks and sanitation facilities. For several decades the Thai R\&D Institute TISTR has worked on developing and testing ISSB, which in other countries are called compressed stabilized earth blocks or CSEB. The composition of building blocks and the quality of building structures determine together the structural quality of the house or building. If there is a need for earthquake- and storm resistance, the building blocks and the structures must have specific features. Building stacked houses is an important issue given the growing scarcity of land for housing and the increasing land prices. ISSB is not only applied in Thailand, but also in Cambodia for low-cost housing and in Nepal for home reconstruction after the 2015 earthquake. ISSB or CSEB is also applied in other countries as an alternative building material and technology to replace the use of fired bricks and concrete building blocks for housing. Reducing the use of cement in the materials and structures is important for environmental reasons, but in ISSB/CSEB the use of cement as a stabilizer cannot always be avoided. This is surely the case in areas where earthquakes, heavy storms and floods can occur. Although this paper focuses mainly on technical aspects of sustainable housing and construction, there is also a focus on social sustainability, meaning a strong involvement of local communities in the production of sustainable building materials for walls, newly developed construction technologies, and mutual house and facility construction.
\end{abstract}

Keywords: interlocking block masonry, interlocking stabilized soil blocks, ISSB, Thailand ISSB, compressed stabilized earth blocks, CSEB, low-cost housing, social housing, mutual housing, sustainable house construction

\section{Introduction}

As part of the ASEAN Next 2019 Conference of the Association of Southeast Asian Nations, the Thailand Institute of Scientific and Technological Research (TISTR), an R\&D Institute under the Ministry of Science and Technology, hosted a workshop entitled: ASEAN Workshop on Green Construction Materials for Community and MSMEs in March 2019 in Bangkok. The workshop had the following aims: to exchange knowledge on green construction materials by involving micro, small and medium-sized enterprises (MSMEs) from the ASEAN member countries; to share technology of TISTR on interlocking block production and construction methods; and to establish an ASEAN cooperative network on green construction materials. TISTR's goal is to further develop and improve the ISSB-technology, in order to promote affordable locally resourced building materials for housing and other structures which are seen as environmentally friendly. TISTR brings the technology to Thailand's regional and local levels to be used by individuals, communities, and MSMEs.

This paper explores the use of ISSB in Thailand, as developed by TISTR since 1967. These interlocking construction blocks are made of local raw materials - earth, loam, or soil - which are mixed in the right proportion with a low percentage of cement, and compressed using simple machinery. The resulting building blocks usually have high compressive strength and are suitable for constructing both outer and inner walls with load-bearing capacity. In addition, there are several other applications, including round water-storage tanks and sanitation facilities for communities. It is widely understood that the use of ISSB for house construction supports green technology, as it is more sustainable than using fired clay bricks or concrete building blocks. The construction processes using ISSB and the associated building technology are not very complicated. Due to the 
fact that raw materials can be found locally, the brick laying process and the building of homes can be done (partly or largely) by the residents themselves, resulting in reduced construction time, and high cost-effectiveness.

Local communities can use ISSB technology for the construction of (individual) homes of good quality as well as community facilities and structures. This might encourage the establishment of new businesses and the creation of jobs, especially in the rural communities and the smaller cities. Involving local households and communities in housing construction can actually be seen as social sustainability which is achieved by the ISSB technology and the transference of knowledge and equipment to local communities. Although the construction technology is not very complicated, the composition of the mixtures remains a specialized matter that always demands professional investigations of soil types to ensure the strength of the structures. Knowledge must be transferred to local communities, producers of materials, contractors, and construction workers. Some properties of the mixtures for the interlocking building blocks could be improved, for example to increase compressive strength of blocks in order to be able to build in multiple stories, and to reduce the water absorption of the walls. Research is being conducted on aspects such as the use of larger spans in building constructions, the strength of load-bearing walls and columns, and the use of (bio-)alternatives to cement as a stabilizer in mixtures for blocks.

\section{Box on Thailand}

Thailand has a population of over 68 million inhabitants. The urbanization rate is 50.4 percent and 12.6 percent of the population is living below the poverty line. Public housing has been provided in Thailand for low-income households mainly in urban areas, for example in the Bangkok Metropolitan Region. The urban housing shortage is huge and for a long time low-rise (4-5 story) apartment buildings were built among others by the National Housing Authority. ISSB is not applied there because stacked housing in high density areas demands different building structures, and soil for ISSBs is not available within urban areas. The housing issues in rural areas, villages, and smaller cities differ from those in the urban areas. Outside of urban areas, houses - modest and middle class - are mostly built by individual households. The ISSB building blocks are most conveniently used for 1 or 2 story houses. This is shown in a book of TISTR containing illustrations of home types on offer. In addition to homes, also schools, community centers, hotels, industrial buildings, etc. can be realized with the ISSB building blocks. The ISSB building blocks are also suitable for families building homes on private land. The modest housing type is model Style a 1, with $45 \mathrm{~m} 2$ floor space. According to TISTR, the houses built with the first generation ISSB - which are already around 35 years old - are still in good condition. The National Housing Authority (NHA) has developed various housing typologies for people with low and moderate income: condominium housing, as well as small houses on their own plots to be expanded incrementally by the residents. Currently, they are developing Green Housing projects for low-income people, and give grants for home renovations and loans for house building (National Housing Authority Thailand, n.d.).

\section{International Focus on Earth Technologies Including ISSB}

After the first human settlements were founded, the residents started to use earth as a building material. Building earthen walls gradually became a specialized craft in most regions of the world, such as Asia, Africa, the Middle East and Latin America. Earth was also used in North America and in some European countries. Various names were used for earthen building materials, such as adobe, compressed or rammed earth, and mud bricks. Using old techniques and adding new technology and additives makes earth building blocks more durable and sustainable, compared to the 'common modern' building materials such as reinforced concrete and steel. Adding a little cement (3-4 percent) to the adobe mixtures greatly improves their resistance (Dethier, 1983). A great quality upgrade was made possible by the development of hand-press devices and mechanized presses. The Cinva Ram press was developed in 1952 by Raul Ramirez in Colombia; the blocks produced with the press were stronger and more water resistant than adobe. Since the 1960s many projects were started with earth techniques to realize housing and other buildings, as was the case in most countries in Africa. In India the Auroville Earth Institute (AVEI) and the Indian Institute of Science of Bangalore (IISc) performed research concerning earth technologies such as CEB and CSEB and developed new knowledge and building standards. The Auroville Earth Institute a highly respected expertise center on Earth technologies and architecture. They have successfully built various buildings with CSEB over the years, including high-quality houses and apartment buildings with three and four stories (Auroville Earth Institute, n.d.). Other countries, such as Thailand and Sri Lanka, also developed CSEB or ISSB and developed their own standards, as did New Zealand, Australia, and the USA. In France, CRAterre-ENSAG promotes earth techniques and is a center of excellence of the UNESCO Chair 'Earthen Architecture, Constructive Cultures and Sustainable development' (Rocha, 2017). 
The search for 'affordable and sustainable building materials for low-cost housing' got a new boost in the first decade of this century by UN-Habitat, which has led to various publications and pilot projects. These projects often used earth technologies, such as compressed (stabilized) earth blocks (CEB; CSEB) and interlocking stabilized soil blocks (ISSB), which are names of the same type of building blocks. These building blocks have environmental advantages and can be used for housing and buildings such as community and medical centers. UN-Habitat is promoting earth technologies for low-income housing because of the environmental benefits and the social and economic advantages of involving local communities and entrepreneurs in block production and house building. A holistic approach on sustainability contains the following aspects: environmental, economic, cultural, social, and institutional. The vision is that local raw materials are used for the composition of building materials for walls and that local labor is involved in construction. Then, houses and other buildings can be built by local people, while simultaneously local building practices are improved by adding upgraded technology. This means that a transfer of knowledge to local communities and small businesses must be performed.

In Africa, low-cost building technologies have been promoted for low-income housing in countries like Kenya and Uganda in order to reduce the building costs and to promote construction capacities in poor communities. This has led to the use of alternative building materials - such as stabilized soil blocks and micro concrete roof tiles. In 2009 UN-Habitat published a document on appropriate earth technologies in Uganda, specifically on interlocking stabilized soil blocks (Pérez-Peña, 2009). It demonstrates how environmentally friendly building materials and construction technologies can be made more affordable and accessible to the urban poor, while meeting strict building standards. Compared to alternatives such as fired bricks, ISSB offers lower construction costs at similar quality, is suitable for a wider range of environments, and significantly reduces the impact on the environment. The ISSB was used for walls for housing, schools, sanitation facilities and kitchens. The walls consist of ISSB blocks built within frames of reinforced concrete, with columns and beams. Thus, the blocks themselves don't normally have to be load bearing. The forms of the interlocking blocks differ from the ones used in Thailand. It has been found that intensive supervision is needed at the start of a project to ensure block quality. Another example of the use of stabilized soil blocks is in Darfur (UN-Habitat, 2010).

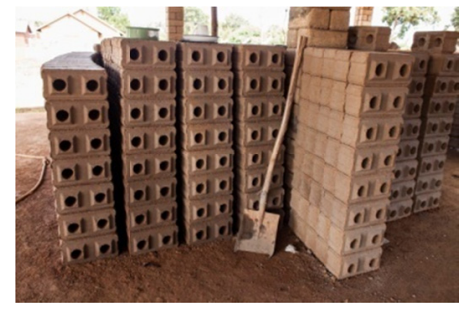

1

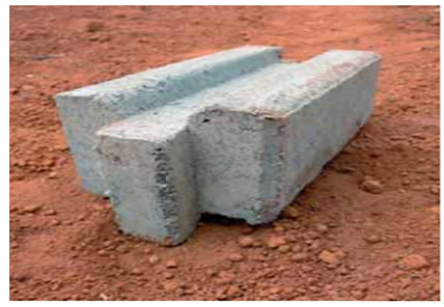

2

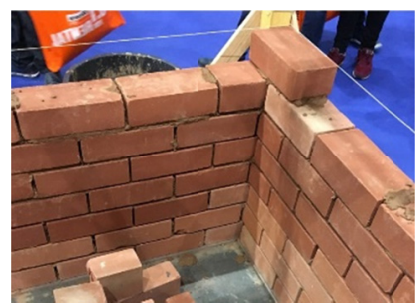

3

Earth Bricks used in Africa: (1) ISSB in Uganda (model 'Tanzania'); (2) interlocking CSEB Uganda; (3) rectangular loam bricks for Mali. Sources: (1) author; (2) UN-Habitat; (3) author. Image 1. Various forms of earthen building blocks/bricks

An additional example in Africa showed the use of earthen building blocks in a project of 300 houses in Bamako, commissioned by the Ministry of Town Planning and Habitat in Mali. Blocks are produced with a mobile factory; the hydraulically compressed earth blocks (HCEB) are also called loam bricks or clay bricks, but are comparable to CSEB and ISSB - but these are not interlocking (LEVS Architects, n.d.). The rectangular loam bricks are laid with mortar of only $0.5 \mathrm{~cm}$. No cement is used in these loam bricks, although for bearing walls a small percentage of lime as a stabilizer is needed. Using earthen materials from the construction site decreases transport and construction cost as well as the environmental impact. Oskam-vf provides the technology and machinery (Oskam-vf, n.d.). The architect Francis Kéré from Burkina Faso designed and built a series of schools in some African countries with comparable compressed earthen building blocks, which are also rectangular in form. The bricks used are stabilized with around 7 percent cement. The architect also built the Center for Earth Architecture in Mopti, Mali, with 7 percent cement added to the CEB for greater stability (Kéré, 2016). This building is in the same city as the great mosque of Mopti, an imposing earthen structure built in traditional style.

Research for the improvement of earth blocks is being conducted in various countries, in order to minimize the use of cement. Therefore, there is an ongoing search for stabilizers made from plant and animal products. Prof. Gernot Minke of the University of Kassel in Germany, a specialist in building with earth, wrote: "Plant juices 
containing oil and latex derived from plants such as sisal, agave, bananas, and Euphorbia herea, usually in combination with lime, are used as a stabilizing coating successfully in many countries. Several reports show that cooked starch and molasses can also be used to enhance stability. This effect is more pronounced if a little lime is also added" (Minke, 2013). The search for stabilizers as alternatives for cement in earth blocks concerns enhancing the durability and water resistance of blocks by using bio-resources as stabilizers. The main challenge is finding bio-stabilizers that can replace cement in CSEB and ISSB for certain usages. This issue is under investigation in various research institutes.

Adobe building blocks have been used in many places including Central America. The following are important issues regarding the use of adobe: (1) blocks have a higher percentage of clay - meaning there is more shrinkage than CSEB/ISSB, (2) adobe keeps a house cool in hot climates, (3) it is mostly used in rural areas where clay-like soil is available, and (4) do it yourself is possible with technical guidance. Adobe is compressed by hand or feet and its dimensions are usually $30 \times 30 \times 9 \mathrm{~cm}$. The structures of the buildings are reinforced with bamboo bars. The walls must always be plastered to avoid the disease of Chagas. The houses built with adobe walls can be built so that they are earthquake resistant. Currently, research is being conducted at FUNDASAL's research center (Foundation for Salvadorian Development and Affordable Housing) in El Salvador on improving the ratios of the mixtures in order to lower the percentage of clay, to reduce shrinkage. Besides that, FUNDASAL also experiments with colored mixtures, adequate mixtures for plasterwork and paint for walls with natural colors. The research is relevant to the development of CSEB and ISSB (Bredenoord, 2017).

\section{The 'Journey' of Thailand's Interlocking Stabilized Soil Blocks}

The Thailand ISSB is a compressed earth (soil) block that is made up of several raw materials, which are mixed in a certain proportion. 'ISSB' is a common abbreviation of the compressed earth block or brick. The dimensions, weight, and form of the blocks can vary internationally; the TISTR interlocking stabilized soil blocks cannot be shifted. These interlocking blocks have been developed as a load-bearing building material with a pattern of holes, which makes possible the addition of horizontal and vertical reinforcements in the walls. The reinforcements are not visible from the outside or the inside, which is an architectural advantage. Stacking the blocks can be done by local people after training, but normally under the supervision of experienced construction workers. By making use of local raw materials such as gravel, sand, silt, clay and loam or suitable waste materials, the use of cement in the mixtures can be reduced which makes the blocks less heavy than the first generation of interlocking blocks. The use of ISSB helps to increase the value of existing natural materials, and can give a boost to the local economy. According to TISTR, the use of ISSB helps to reduce construction costs by more than 20 percent compared to conventional materials. The ISSB that is known in Thailand has a development history of several decades. A first interlocking building block was introduced in 1982, but that turned out to be too heavy in use. Vertical grooves were made on the outside, but the owners/residents did not like that too much. Consequently, the second block model for homes had no exterior groves. The shape and dimensions of the blocks were improved over the years mostly as a result of the practical experiences. Model 3 has been developed with two holes to connect the bricks in vertical direction for better interlocking functioning. Models 3 and 4 are suitable for regular building applications (Janbunjong, 2019).

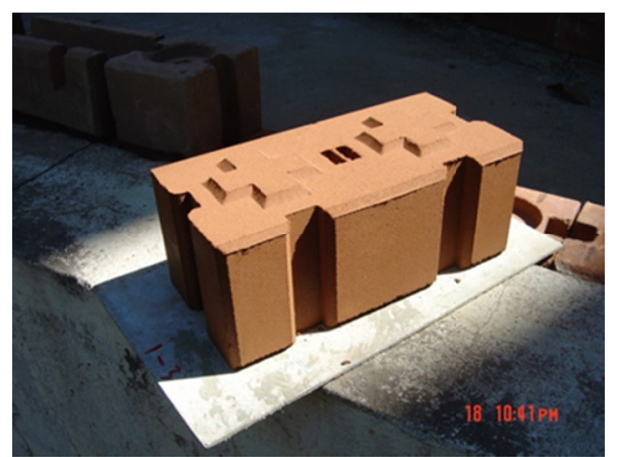

TISTR IB, Model 1 (1982)

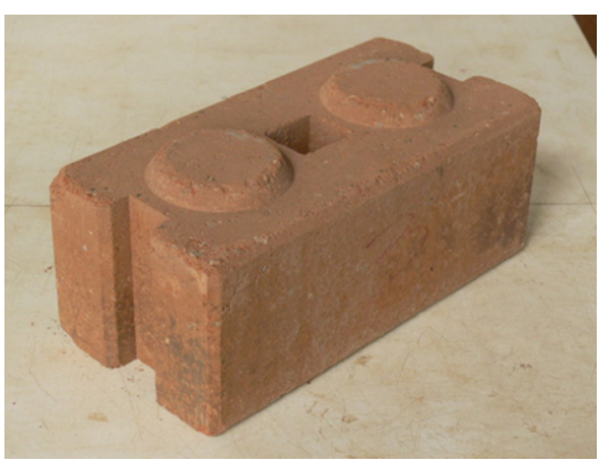

TISTR IB, Model 2 (1998) 


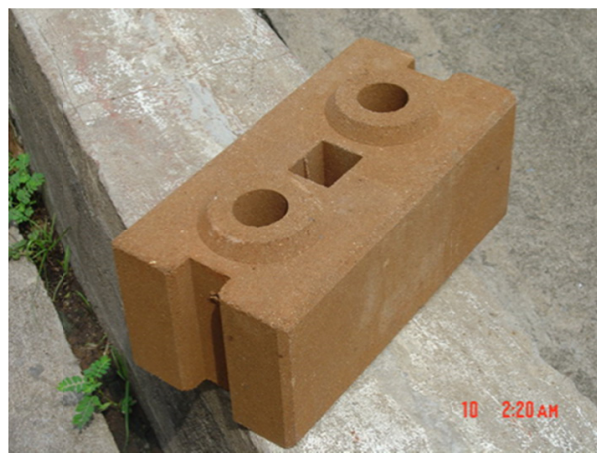

TISTR IB, Model 3 (actual)

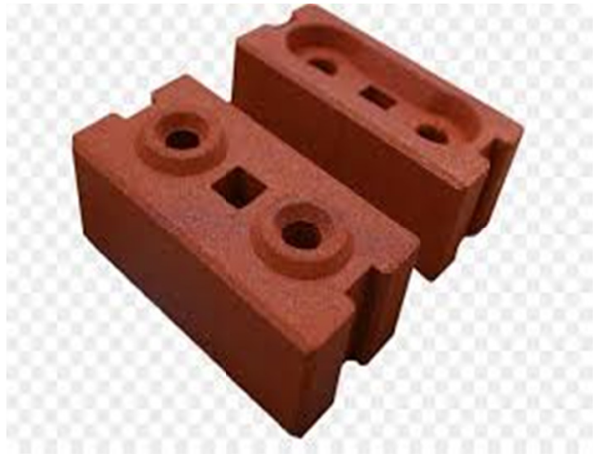

TISTR IB, Model 4 (current with link-hole depression for more than 2 story bearing)

Source: TISTR.

Image 2. TISTR IB block model 1-4

At the beginning of 2019, TISTR began working on the next generation of improved building blocks; (1) blocks that are suitable for load-bearing walls in stacked homes with more than two floors, and (2) lightweight hollow panels that can be used for interior walls. Naturally, the new compressed blocks and their mixtures were tested on the most relevant properties and its functioning in the houses' structures. The provision of the building blocks has changed over the course of time. Before 1998 the TISTR interlocking block method was taught to the rural communities to build their own houses. After 1998, the sale of the blocks took place at the factory - 665 factories are spread out all over the country - and a house construction package became possible. In 2012, construction material retailers emerged with retail prices, free delivery services, and a house construction package. In 2017, the construction material is also offered in the online market with its traders and retailers, free delivery services, and a house construction package. In the table below some wall materials in Thailand are compared. It shows that ISSB has advantages over other materials as fired bricks and blocks of cement.

Table 1. Comparison of wall materials properties in Thailand (Source TISTR)

\begin{tabular}{lllll}
\hline Properties of bricks/blocks & Normal Brick & Cement Block & Light Weight Block & Interlocking Block ISSB \\
\hline Dimension (cm) $\mathrm{w}^{*} \mathrm{~h} * \mathrm{~d}$ & $15 * 6 * 7$ & $40 * 7 * 20$ & $60 * 7.5 * 20$ & $25 * 10 * 12.5$ \\
& & & $60 * 10 * 20$ & \\
Compressive strength (ksc) & $20-40$ & $10-15$ & $30-80$ & $<70$ \\
Water absorption (\%) & 40 & - & 30 & $15<$ \\
Mortar height (cm) & $1.5-2$ & $1.0-1.5$ & $0.2-0.3$ & Grout \\
Plastering $(\mathrm{cm})$ & $1.5-3$ & $1.5-3$ & $1.0-1.5$ & No \\
Wall bearing & No & No & No & Yes \\
\hline
\end{tabular}

\subsection{How the ISSB Building Blocks Are Made, and the Walls Built}

During the ASEAN Workshop on Green Construction Materials for Community and MSMEs in March 2019, experts and researchers took part in the workshops; they were from TISTR, executives of private companies that produce interlocking building blocks, researchers, and architects. Participants were from Vietnam, Cambodia, Malaysia, the Philippines, and Indonesia, and two international consultants came from Australia and the Netherlands respectively. Several presentations were given by scientists from TISTR and the previously mentioned countries. The building blocks were produced on the location of TISTR, also called Technopolis, and the next day placed in a trial set. The composition of the mix for the ISSB was determined in advance. The raw materials, namely sand, laterite (containing sand/silt and clay) and cement, were mixed and then the building blocks were compressed, making use of both a hand press and a mechanized press. 


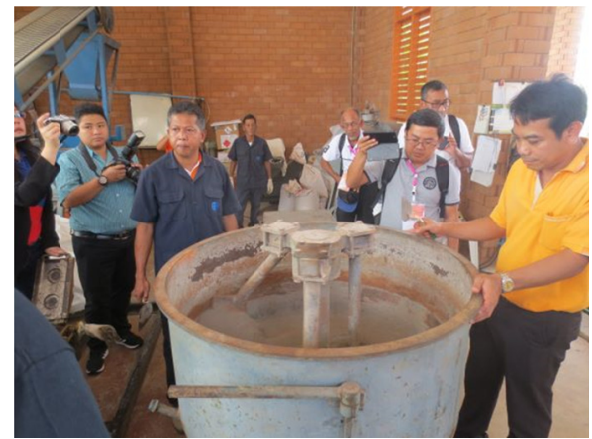

Mixing machine

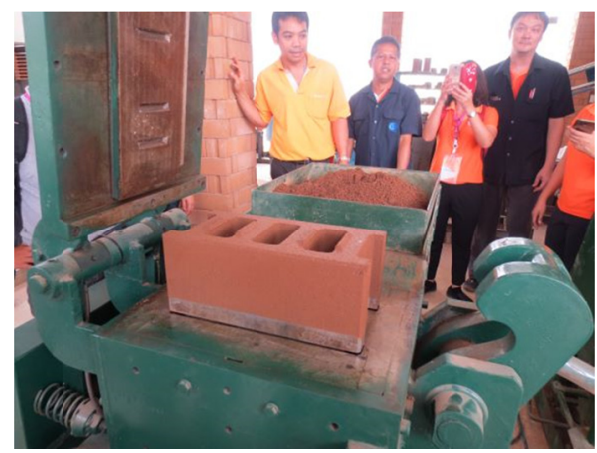

Blocks to be used for load-bearing walls, coming out of a mechanized press

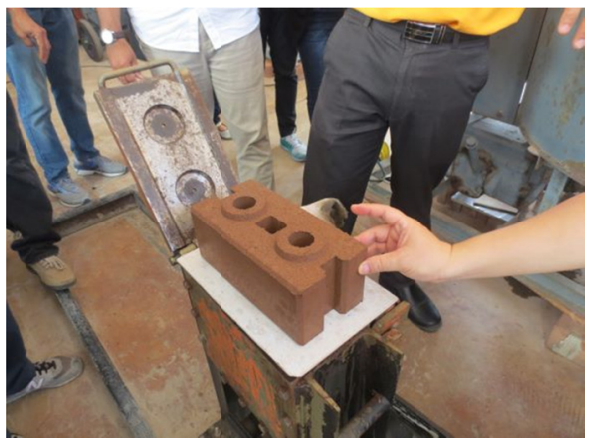

The block out of the hand press

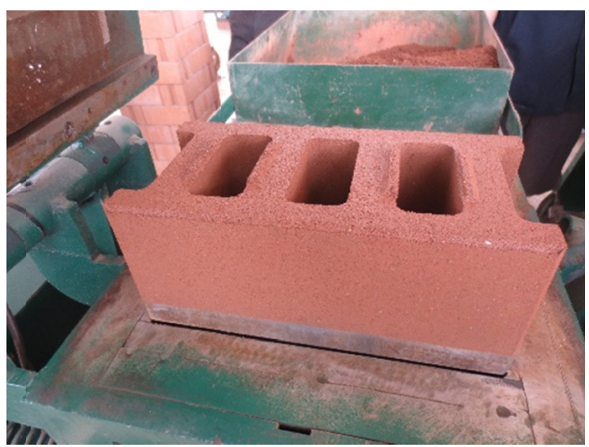

Source: author.

Image 3. The production process of ISSB in Thailand

A first layer of building blocks was laid directly; the first layer needs to be positioned carefully. The next day, a wall was built and the attendees were invited to participate and to comment. Many important comments were made by entrepreneurs from Cambodia and Malaysia who themselves own a building blocks factory. The blocks that were pressed the day before were used. The following aspects were noted:

- reinforced corner joints

○ horizontal reinforcements

- vertical reinforcements

- finish of the reinforced top layer

- filling the vertical holes with cement

○ treatment of the outside with a water-repellent coating.

1

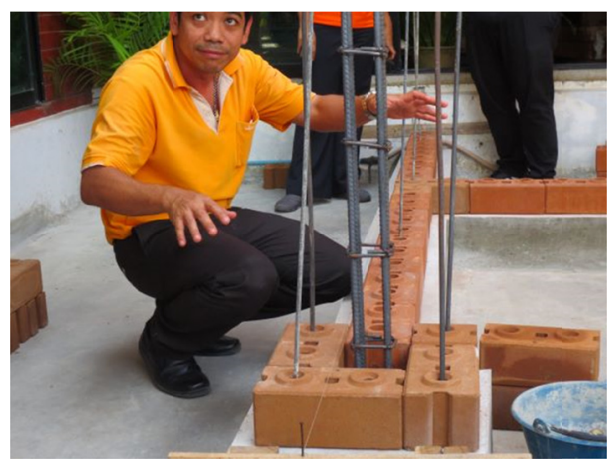

2

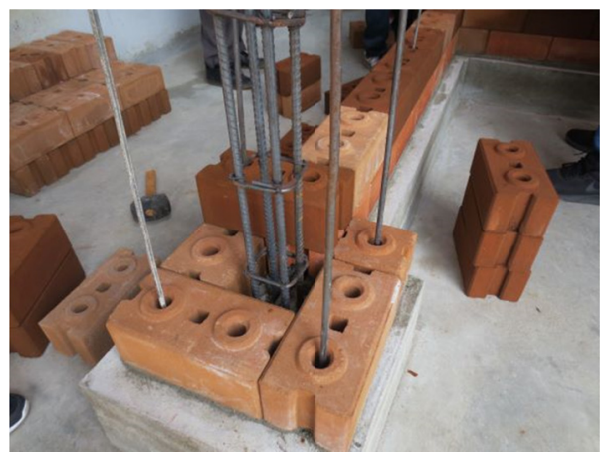


3

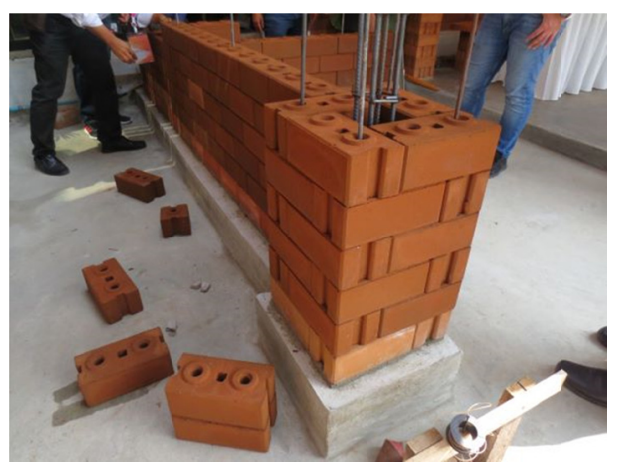

4

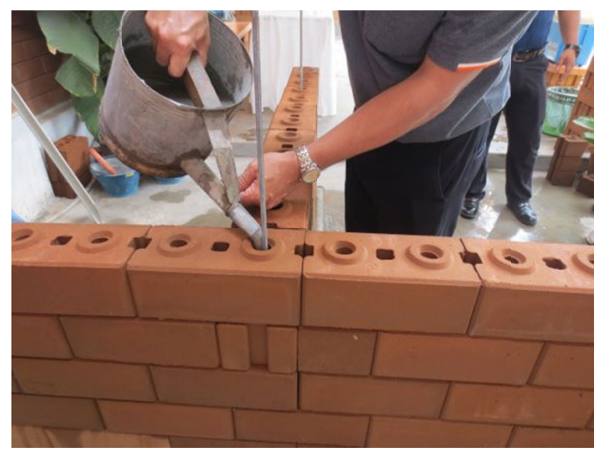

Source: author.

Image 4. The process of constructing walls with ISSB (1-4)

\subsection{Testing the ISSB}

TISTR has tested the compressed building blocks through the years concerning the next properties (Kokkamhaeng, 2019):

- Compressive strength; in wet and dry condition (7 MPa)

- Compressive strength dependent on density of block and cement ratio

- Water absorption capacity; with variations of cement ratio and density

- Flexural bond strength

- Optimum ratio of grout mortar: Portland cement per course sand is $1: 2$ and w/c 0.75

Testing columns and walls under various circumstances in full scale load test:

○ Capacity of Interlocking Block Columns

- Capacity of TISTR Interlocking Block Beams for 3, 4- meter long beams

- Testing of 2.5-meter-long wall with a 1-meter door opening

○ Behavior of TISTR interlocking block wall under lateral load

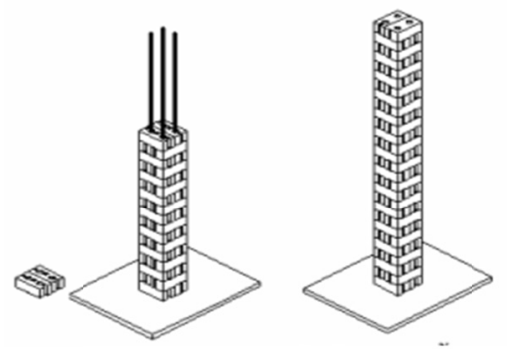

Type A : Two blocks column

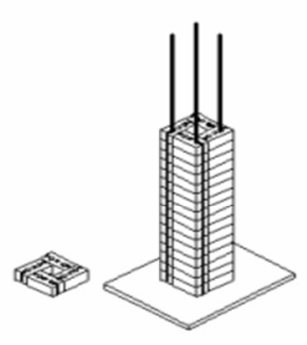

Type B : Four blocks column

Source: TISTR

Image 5. Columns tested by TISTR

In addition, to protect against environmental disasters, more tests under severe conditions were performed as follows:

- Behavior of walls under conditions of severe flooding

- Behavior of walls under conditions of earthquakes

$\circ$ Behavior of walls in the event of tsunami 
Currently, there is no specific Standard for Interlocking Block in Thailand; therefore TIS 57-2533 (Standard for hollow load-bearing concrete masonry units: Thailand Industrial Standard) has been applied. Ultimate testing results on all properties are much higher than allowable; and a design code is required. The safety of TISTR interlocking blocks has been proven in all sorts of buildings, columns and walls under many circumstances. It must be said that all tests were executed by TISTR, who has advanced equipment to carry out all necessary tests.

\subsection{Architectural quality of ISSB}

The walls of houses and structures built with ISSB are of high architectural quality, which makes ISSB applicable for all kinds of housing types, from low-cost to high-end.

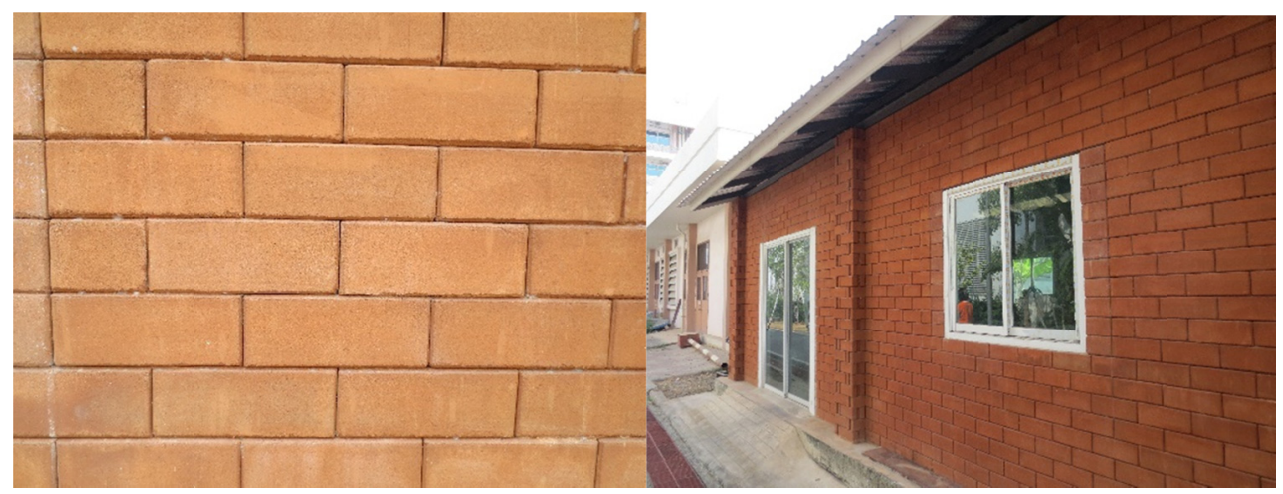

Photos above are taken at the TISTR testing center where a house was built. Source: author.

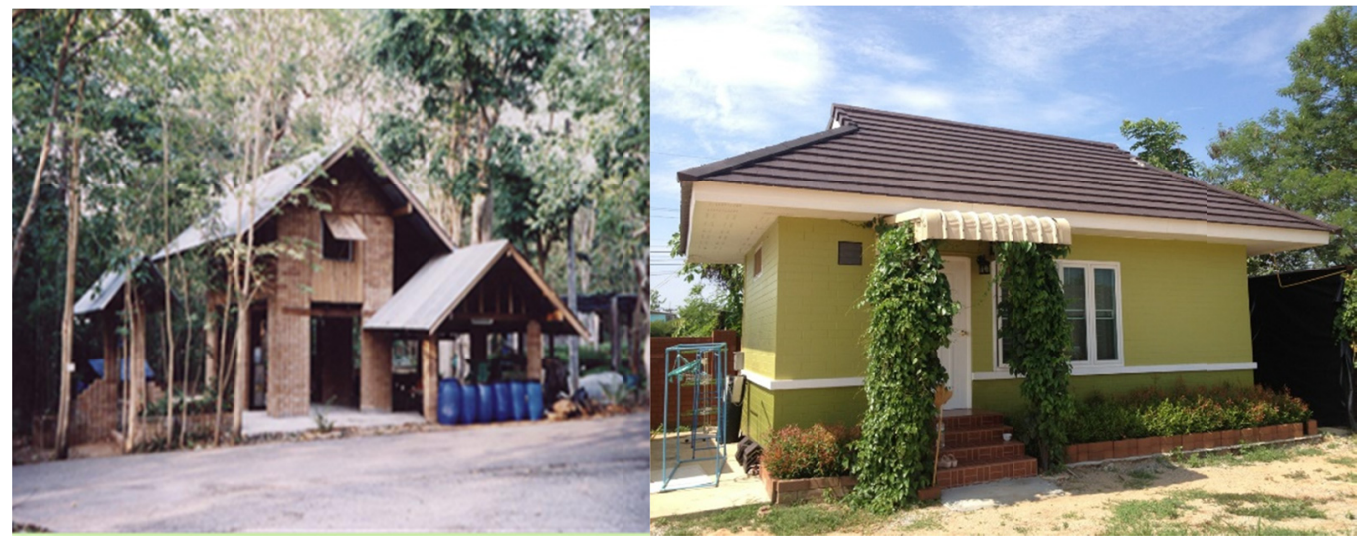

A 35-year-old house built with ISSB (Source: TISTR) House in Chiang Rai built with ISSB. 2014. Source: TISTR

Image 6. Architecture of realized structures

\section{Transferring Building Knowledge to the Country's Regions}

The government of Thailand wants to bring the newly developed knowledge to regions where it can be put into practice. This concerns many areas of science. The ISSB interlocking blocks can be well used in communities, especially if the soil for the blocks is sourced locally. TISTR promotes such projects and gives accompanying training, so the knowledge is being transferred in a good way, while the quality of building structures is assured by supervision over building activities. Dr. Aparat Mahakhant, deputy-governor Research and Development for sustainable development of TISTR, presented during the March 2019 Workshop two examples: the Karen group - a population group in the North of Thailand - would like to build a water storage tank and to build homes. This was done in collaboration with the Karens for Christ Foundation in Chiang Mai; the population participated actively herewith. Eventually, that led to the construction of a water tank and sanitation facilities. In another case, TISTR transferred knowledge and together with local people a Buddhist temple was built in Udon Thani. Communities can develop economic activities in the form of a community enterprise (group). Such a form of cooperation can be a small or medium enterprise to produce TISTR building blocks, sell them to the public and give technical assistance to self-building households and groups. 


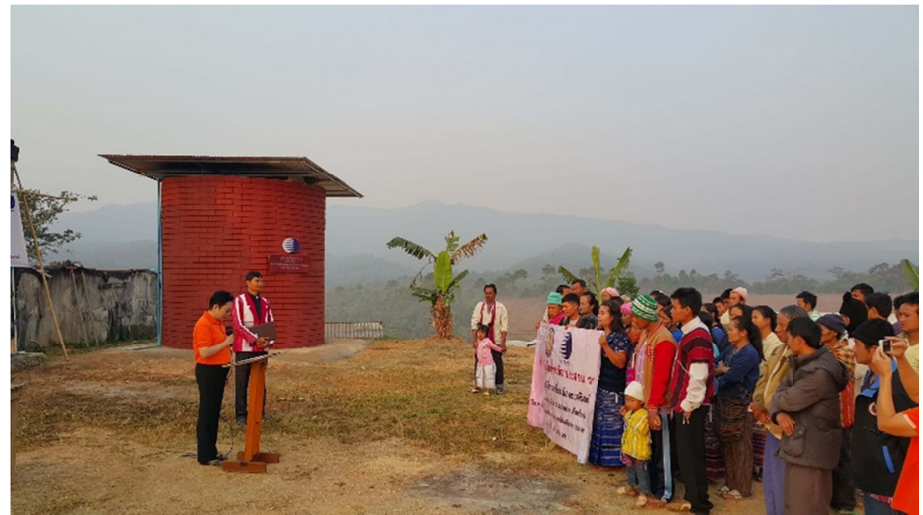

Source: TISTR.

Image 7 . Water storage tank built with the Karen community

In other cases, the transfer of knowledge is done by entrepreneurs who have set up a building blocks factory. Here, building blocks and other materials are produced and sold to households and businesses. The entrepreneur can be responsible for providing technical assistance to self-building households and groups, and offer a housing package. In addition, these entrepreneurs also act as contractor. This is a challenge because many tasks are combined, while the entrepreneurs must be able to earn a profit from their enterprise. Control over the quality of construction blocks and their physical properties is vital. The philosophy regarding the dissemination of the new technology is good, but it is often a challenge to implement it effectively. Normally, the local authorities have specific tasks in supervising the building activities, making building regulations, and executing building control. The functioning of technical assistance and the role of local - municipal - building control might be clarified.

\section{Suitability of Thailand's ISSB for Low-Cost Housing}

The ISSB technology as developed by TISTR is suitable for all kinds of housing, from low-cost to middle- and high-income housing solutions. As the demand for low-cost housing is high in Thailand, application of ISSB in low-cost social housing and in housing programs to support self-construction could be considered. The National Housing Authority (NHA) is a government enterprise that provides housing for low- and middle-income earners and delivers financial assistance to them for land acquisition and decent house building, in order to develop strong and self-reliant communities. NHA started carrying out the housing program Baan Eua Arthorn (BEA), which aims to produce hundreds of thousands of affordable housing units. Additionally, the function of NHA's Urban Community Development Office (UCDO) is to grant subsidies and loans to community savings groups, for example for the purchase of land and the construction or improvement of homes. Organizing local communities to help them become self-reliant communities is one of UDCO's main tasks. By 2000 many community savings groups had been formed in various provinces. UCDO provided loans and technical support and established community networks. In the same year, UCDO fused with the Rural Development Fund to become the Community Organization Development Institute (CODI), now a public organization with great autonomy to mobilize resources. Providing for green housing development for low-income people is the next challenge. A series of housing types were developed, such as row-houses of three, two and a half, and two stories, two-story detached houses, and two-story duplexes. TISTR's approach to spreading the eco-building blocks and its technology to all regions of Thailand is the same as that of UDCO and CODI. Involving local communities in the building of water tanks and sanitary facilities is also done in a comparable, participatory way. Housing projects in small cities and rural areas might be supported by NHA and executed using the TISTR building blocks technology (CODI, n.d.).

\section{Future R\&D on ISSB and Structures of Housing and Buildings}

Building blocks as developed by TISTR are suitable for low-cost and low-rise housing, and for green collective housing projects. The blocks are also suitable for housing for individual families who self-build and expand their homes over time. In the latter case, technical assistance is required, but Thailand's housing institutions are capable of delivering such services, including assistance for save-and-build groups and housing cooperatives. It is to be expected that social (collective) housing has great potential for the application of sustainable and durable building materials, such as ISSB, especially in rural areas and smaller cities.

TISTR focuses, among other things, on the use of residues and biomass. Since a relatively large amount of cement is still used in the IBBS technology, it is to be expected that TISTR will search for replacements for (a 
portion) of the cement. Current cement use in ISSB is twofold: 1) there is a relatively high percentage of cement in the mixtures of the blocks themselves, and 2) strong cement is used in vertical and horizontal cavities that function as columns; some are reinforced with a steel bar and others are not. TISTR might research the use of lime, and bio-based stabilizers, such as enzymes and bio-resins for use in ISSB. Such research is being done internationally and TISTR could easily follow those studies, and focus on research of applications of locally or regionally available inorganic as well as organic resources.

Currently, the constructive strength of the reinforced wall consisting of ISSB is determined by the vertical bars and cement fillings. It gives the wall a structural strength comparable to a massive concrete wall, which is not necessary in one-story houses. The desired structural strength could be provided by iron tensile bars to be anchored in the foundation, so the blocks do not have to be laid with mortar and can even be reused later. Non-bearing walls can be built with blocks that have less compressive strength and a lower percentage of cement. Research could clarify such possibilities and others, which might allow builders to minimize the use of cement in wall construction, while the building blocks can be re-used later elsewhere, which is not the case in current cement-filled ISSB.

\section{The Use of ISSB for Housing in Cambodia}

In Cambodia, the ISSB technology used is comparable to ISSB as developed in Thailand, but it is not yet widespread. The following example clarifies the housing practice in Cambodia. The social entrepreneur Kongngy Hav from Phnom Penh, Cambodia established an ISSB brick factory and has developed 'My Dream Home', a concept designed to provide quality and affordable green housing. It utilizes the interlocking brick system, designed to provide durable construction that can be put together by people without building skills. Through the initiative, an average small two-story home can be built for between US $\$ 4,000$ and US $\$ 6,000$, including design and technical assistance on the construction. According to the entrepreneur, a dwelling is $20-40$ percent cheaper than traditional housing, is less labor intensive and is better for the environment. The bricks, made from soil, sand and clay, are also aesthetic for modern building and do not harm the environment when they are made. The use of cement is minimized herewith. The firm also builds more expensive houses and other structures (My Dream Home, n.d.). The NGO Habitat for Humanity has built a housing project with earthen blocks for at least 15 safe, high-quality, and affordable homes in the Battambang Province in the northwestern part of Cambodia. The project uses primarily compressed earth blocks (CEB), a building material that is made mainly from damp soil compressed to form blocks. CEB technology has been developed for low-cost construction, as an alternative to adobe to promote the use of eco-friendly construction materials within communities (Habitat for Humanity Cambodia, 2017).

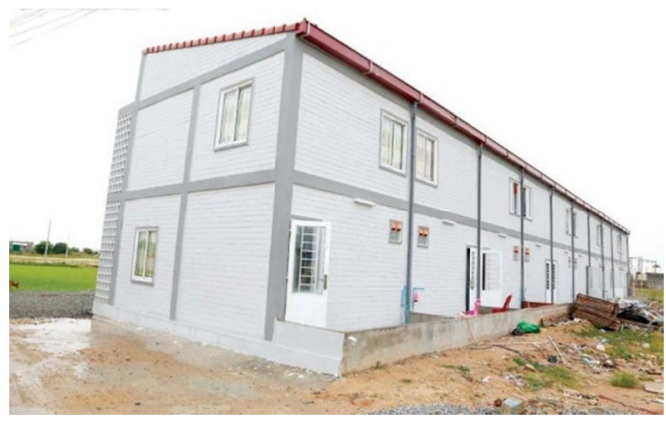

Source: Kongngy Hav.

Image 8. Low-cost housing type by 'My Dream Home'

\section{The Use of CSEB for Housing Reconstruction in Nepal}

Nepal is a disaster-prone country where many natural disasters occur regularly. In Nepal the use of CSEB increased after the 2015 earthquake, which destroyed almost 200,000 homes and damaged approximately 175,000 homes. Thousands of people were killed and many severely hurt. Build-up-Nepal as a social enterprise helps local communities rebuild their own homes using local raw materials. Together with other aid-organizations and local entrepreneurs, they delivered the necessary training and the machinery to local actors. In principle, the villagers build up their own homes with interlocking earthen building blocks, making the homes earthquake resistant also due to the designed building construction for the whole house. They executed low-cost 
housing projects, community centers, and schools with CSEBs - comparable to ISSB in Thailand. It is done by community-driven and entrepreneurship-driven reconstruction (Build-up-Nepal, n.d.). Build-up-Nepal has started rebuilding 90 villages in various regions of Nepal, and mentioned the following advantages of earthen brick technology over building with fired bricks:

○ Earth technology is 25 - 40 percent cheaper, making it affordable for poor rural families.

- Utilization of local materials results in 60 percent less $\mathrm{CO} 2$ emissions.

- The market for the earthen brick construction technology is applicable across Nepal, beyond earthquake affected communities, where many families also live in poor and unsafe housing.

- Building method is easy to learn for local people, resulting in many women now actively engaged in the reconstruction, some groups have started their own earthen brick enterprises.

This CSEB technology is approved and recommended by the government of Nepal, which established regulations for the use of this and other building materials and construction technologies (Government of Nepal, 2017). In Thailand and India, the same technology was successfully applied earlier and likewise in earthquake-affected areas.

\section{Conclusions and Afterthoughts}

The development of ISSB and related construction technology in Thailand indicates positive results in the field of sustainable construction of homes and other buildings. The technology has spread across Thailand, so that households in the rural areas and smaller cities can make use of it. Application of ISSB is more environmentally friendly than using fired bricks and concrete building blocks. With the ISSB technology developed by TISTR, load-bearing walls can be built with internally reinforced structures or frames, which are not visible from the outside. This technology makes it possible to build earthquake and storm-resistant structures. TISTR, as Thailand's research and development Institute, is capable of further developing these building materials and construction technology, and it can execute all necessary testing in a scientific way. On a practical level, ISSB technology is being propagated across all provinces, with the involvement of many MSMEs. Thailand's development policy is also based on bringing knowledge to local communities also in smaller cities and rural areas. This is happening with the outlined developments with earthen technology ISSB too. In Cambodia, the ISSB technology is also applied, among other things for low-cost housing. In this paper, an example of homes built by a social entrepreneur is described. Habitat for Humanity also uses compressed earthen blocks in a social housing project. The development of ISSB in this country is still relatively small-scale. Entrepreneurs face difficulties in getting funding for their low-cost housing products. In Nepal, ISSB technology was applied after the earthquake of 2015, as is apparent from the efforts of the aid organization Build-up-Nepal. There are many applications of ISSB technology for the reconstruction in villages, such as for homes, community facilities and schools that were built or rebuilt. SMEs were established and started to further apply the ISSB technology in the regions where it is needed. It's a great benefit that the government has approved the application of ISSB for housing projects. Finally, the development of the ISSB technology may benefit from maintaining the ASEAN network for sustainable building materials, including exchange of knowledge and standardization of the materials. Research programs could be set up jointly. Further limiting the percentages of cement in the mixtures and the building structures would be an interesting research question. Some other research questions are described in this paper. It's a challenge to match ISSB technology with the housing programs that are developed by the NHA of Thailand.

\section{Acknowledgements}

The authors thank entrepreneurs Mr. Kongngy Hav and Mr. Menglong Seng of My Dream Home in Phnom-Penh, Cambodia, for sharing information on low-cost housing with ISSB.

\section{References}

Auroville Earth Institute (n.d.) Compressed Earth Blocks. Retrieved from http://www.earth-auroville.com/compressed_earth_blocks_en.php

Bredenoord, J. (2017). Sustainable Building Materials for Low-cost Housing and the Challenges Facing their Technological Developments: Examples and Lessons Regarding Bamboo, Earth-Block Technologies, Building Blocks of Recycled Materials, and Improved Concrete Panels. J. Archit Eng Tech, 6, 187. https://doi.org/10.4172/2168-9717.1000187

Build-up-Nepal (n.d.) Interlocking bricks and Projects. Retrieved from https://www.buildupnepal.com/interlocking-bricks/ and https://www.buildupnepal.com/follow-our-projects/ 
CODI (n.d.) Housing Prototypes. Retrieved from http://www.codi.or.th/housing/HousingPrototypes.html

Dethier, J. (1983). Down to Earth. Adobe architecture: an old idea, a new future. New York: Facts on File, Inc.

Government of Nepal. (2017). Design Catalogue Volume II for reconstruction of Earthquake Resistant Houses. Kathmandu: Ministry of Urban development. Retrieved from https://www.buildupnepal.com/wp-content/uploads/2017/04/DESIGN-CATALOGUE-VOLUME-II-FINA L.pdf

Habitat for Humanity Cambodia. (2017). Cambodia Big Build. Project Information. Battambang, Cambodia. Retrieved from http://habitatcambodia.org/cbb-project-information-2017/

Janbunjong, P. (2019). Journey of ISSB Interlocking Block Technology. Presentation to the ASEAN Next 2019 Conference: Workshop on Green Construction Materials for Community and MSMEs'. Bangkok: Expert Centre of Innovative Materials, TISTR.

Kéré. F. (2016) Radically simple. Architectur Museum der TU München. Berlin: Hatje Cantz Verlag.

Kokkamhaeng, W. (2019). Properties and Research on TISTR Interlocking Block. Presentation to the ASEAN Next 2019 Conference: Workshop on Green Construction Materials for Community and MSMEs'. Bangkok: Expert Centre of Innovative Materials, TISTR.

LEVS Architects (n.d.). Two worlds, one thought. LEVS Architects reflects on work in Mali and the Netherlands. Amsterdam, LEVS Architects.

Minke, G. (2013) Building with Earth. Design and Technology of a Sustainable Architecture. Basel: Birkhäuser Verlag.

My Dream Home (n.d.). Guide to Best Practice for Construction with My DH Bricks. Build House. Build Hope. Retrieved from www.ourdreamhomes.biz

National Housing Authority Thailand (n.d.). Retrieved from https://www.nha.co.th/view/2/home\#OUR\%20PROJECT

Oskam-vf (n.d.). Retrieved from https://www.oskam-vf.com/English-index.html

Pérez-Peña, A. (2009). Interlocking Stabilized Soil Blocks. Appropriate earth technologies in Uganda. Nairobi: UN-Habitat.

Rocha, M. (2017) CEB Dossier - Vale das Lobas. Badajoz, Spain: CEDACTerra. Retrieved from http://www.valedaslobas.com/wp-content/uploads/2017/03/CEB-DOSSIER-v1.1-en.pdf

UN-Habitat. (2010). Darfur Early Recovery, Stabilized soil blocks for sustainable urban growth. Nairobi: UN-Habitat.

\section{Copyrights}

Copyright for this article is retained by the author(s), with first publication rights granted to the journal.

This is an open-access article distributed under the terms and conditions of the Creative Commons Attribution license (http://creativecommons.org/licenses/by/4.0/). 